\title{
CRESCIMENTO DE PLANTAS JOVENS DE NIM-INDIANO (Azadirachta indica A. Juss. - MELIACEAE) SOB DIFERENTES REGIMES HÍDRICOS ${ }^{1}$
}

\author{
Marcio de Oliveira Martins², Rejane Jurema Mansur Custódio Nogueira ${ }^{3}$, André Dias de Azevedo Neto ${ }^{4}$ \\ e Mauro Guida dos Santos ${ }^{5}$
}

\begin{abstract}
RESUMO - Este trabalho teve por objetivo avaliar o crescimento de plantas jovens de nim-indiano (Azadirachta indica A. Juss.) submetidas a diferentes regimes hídricos. O delineamento experimental foi inteiramente casualizado, com sete tratamentos $(100,80,60,40$ e $20 \%$ da capacidade de pote, suspensão de rega e reirrigado). Avaliaram-se, semanalmente, a altura, número de folhas e diâmetro do caule. Ao final do experimento, as plantas tiveram seus órgãos separados e levados à estufa para obtenção da matéria seca das folhas, caule, raízes e total e, ainda, alocação de biomassa nas folhas, caule e raízes. Também foram calculadas a área foliar, a razão de área foliar e a área foliar específica. O déficit hídrico diminuiu a altura, número de folhas e diâmetro do caule das plantas nos tratamentos mais severos. Os efeitos do estresse também foram observados na redução da matéria seca das folhas, caule, raízes e total e na alocação de biomassa para as folhas. A área foliar também apresentou reduções, mas a razão de área foliar e a área foliar específica não diferiram entre os tratamentos. As plantas reirrigadas mostraram recuperação, principalmente evidenciada pela emissão de novas folhas. Desse modo, sugere-se que para máximo crescimento o nim deve ser cultivado, na fase inicial de desenvolvimento, com $80 \%$ da capacidade de pote.
\end{abstract}

Palavras-chave: Azadirachta indica, Estresse hídrico, Matéria seca e alocação de biomassa.

\section{GROWTH OF THE NEEM (Azadirachta indica A. Juss. - MELIACEAE) SEEDLINGS UNDER WATER DEFICIT}

\begin{abstract}
This work was performed aiming to evaluate the growth of neem seedlings (Azadirachta indica A. Juss.) under water deficit. The experimental design was entirely randomized, with seven treatments (100, 80, 60, 40 and 20\% of field capacity, without water and re-watering). The height, number of leaves and stem diameter were analyzed weekly. At the end of the experiment, dry matter of the leaves, shoots, roots, root to shoot ratio and biomass allocation in leaf, stem and roots were determined. Leaf area, leaf area ratio and specific leaf area were also calculated. Water stress reduced the height, number of leaves and shoot diameter in the plants of the several treatments. Water stress reduced leaf, stem and root dry matter. Only the biomass allocation to leaves was reduced. Leaf area was also reduced; however, there were not significant differences for leaf area ratio and specific leaf area. The recovery of the re-watering plants was evident by emitting new leaves. The results suggest that neem seedlings must be cultivated, in the initial phase of development, under $80 \%$ of field capacity, with maximum production.
\end{abstract}

Keywords: Azadirachta indica, Water stress, Dry matter and biomass allocation.

\section{INTRODUÇÃO}

Atualmente, cerca de $70 \%$ da água potável disponível no mundo é utilizada na agricultura e 40\% dos alimentos são produzidos em solos irrigados. A disponibilidade hídrica é considerada um dos fatores de maior efeito sobre a produtividade agrícola, sendo o fator que rege a distribuição das espécies nas diferentes zonas climáticas do globo (PIMENTEL, 2004). Por esse motivo, nas décadas recentes as bases moleculares e fisiológicas das respostas vegetais à seca têm sido

\footnotetext{
${ }^{1}$ Recebido em 22.10.2008 e aceito para publicação em 02.03.2010.

${ }^{2}$ Doutorado em andamento em Bioquímica pela Universidade Federal do Ceará. E-mail: <momartins@yahoo.com.br>.

${ }^{3}$ Universidade Federal Rural de Pernambuco, UFRPE, Brasil. E-mail: <rjmansur1@gmail.com>.

${ }^{4}$ Universidade Federal do Recôncavo da Bahia, UFRB, Brasil. E-mail: <azevedo_neto@yahoo.com.b>.

${ }^{5}$ Universidade Federal de Pernambuco, UFPE, Brasil. E-mail: <mauroguida@yahoo.com.br>.
} 
o foco principal de estudos intensos realizados por diversos pesquisadores (SADRAS e MILROY, 1996; YORDANOV et al., 2000; GRIFFITHS e PARRY, 2002; TYERMANN et al., 2002; LUU e MAUREL, 2005; JONES, 2007).

Todos os aspectos de crescimento e desenvolvimento das plantas são afetados pela deficiência hídrica nos tecidos, causada pela excessiva demanda evaporativa ou limitado suprimento de água. Como consequência dessa deficiência, ocorre desidratação do protoplasto, resultando na diminuição do volume celular e aumento na concentração de solutos. Dessa maneira, o processo de crescimento, principalmente em expansão, dependente da turgescência celular e é o primeiro afetado quando em situações de déficit hídrico (NOGUEIRA et al., 2005). Sadras e Milroy (1996) afirmaram ainda que expansão celular, síntese da parede celular e síntese proteica nos tecidos de crescimento estão entre os processos mais sensíveis ao déficit hídrico.

O interesse pelo nim-indiano (Azadirachta indica A. Juss.), árvore nativa do Sul asiático, tem crescido pelas diversas características interessantes do seu extrato bruto ou do seu óleo vegetal, que podem ser extraídos das folhas, caules e sementes. Essas características, que vão desde o combate às pragas agrícolas até o uso medicinal e na indústria cosmética, têm atraído a atenção de pesquisadores em todo o mundo, o que pode ser confirmado pelo número crescente de trabalhos publicados sobre essa espécie (WEWETZER, 1998; KULKARNI et al., 1999; ARAÚJO et al., 2000; OKEMO et al., 2001; ROOP et al., 2005).

Diante disso, este trabalho teve por objetivo estudar o crescimento de plantas jovens de nim-indiano (Azadirachta indica A. Juss.) quando submetidas a diferentes regimes hídricos.

\section{MATERIAL E MÉTODOS}

O experimento foi conduzido em casa de vegetação do Laboratório de Fisiologia Vegetal da UFRPE, entre abril e junho de 2007, com período experimental de 60 dias durante o qual a temperatura mínima e máxima foram, respectivamente, de 27,2 e $35,6^{\circ} \mathrm{C}$, a umidade relativa do ar variou de 39,6 a $76,6 \%$ e o déficit de pressão de vapor mínimo e máximo foi de 0,685 e 3,487 KPa, respectivamente.

Revista Árvore, Viçosa-MG, v.34, n.5, p.771-779, 2010
As mudas de nim-indiano (Azadirachta indica A. Juss. - Meliaceae) foram cedidas pela Estação Experimental de Itapirema (IPA) - Goiana-PE, propagadas a partir de sementes obtidas de uma matriz da mesma instituição, que foram inicialmente semeadas em sacos de polietileno com capacidade para $2 \mathrm{~kg}$, tendo como substrato uma mistura de terriço vegetal, argila e matéria orgânica na proporção de 2:1:1 v/v. As mudas selecionadas para este experimento tinham um mês de idade e apresentavam $10 \mathrm{~cm}$ de altura e cinco folhas, em média. Estas foram transplantadas com a raiz nua para vasos preenchidos até $5,5 \mathrm{~kg}$ com solo (classificado como franco-arenoso) obtido do campus de Dois Irmãos, da UFRPE.

O delineamento experimental foi inteiramente casualizado, com seis tratamentos (regimes hídricos): 100 (controle), 80, 60, 40, 20\% da capacidade de pote e suspensão de rega (SR), com oito repetições cada, totalizando 48 plantas. Aos 30 dias de experimentação, três repetições do tratamento SR foram irrigadas até atingir $100 \%$ da capacidade de pote e não receberam água durante o restante do experimento. Essas plantas formaram o tratamento Reirrigado (R).

Durante 20 dias de aclimatação (após o tratamento), as plantas foram mantidas na capacidade de pote, previamente estabelecida pelo método gravimétrico, segundo Souza et al. (2000). Após esse período, iniciou-se a aplicação dos tratamentos por meio de pesagem diária de cada pote, onde foi adicionada água até atingir o peso correspondente de cada tratamento.

A avaliação de crescimento foi realizada semanalmente, aferindo-se altura das plantas (AP), diâmetro do caule (DC) e número de folhas (NF). Ao final do experimento, as plantas foram separadas em folhas, caules e raízes, pesadas e acondicionadas em sacos de papel para secagem em estufa de circulação forçada de ar com temperatura de $65{ }^{\circ} \mathrm{C}$ até peso constante. Após a secagem desse material, foram obtidos os valores da matéria seca e calculadas as alocações de biomassa nas folhas (ABF), caule (ABC) e raízes (ABR).

A área foliar também foi determinada no fim do experimento. Para tal, foi feita a pesagem das folhas de cada uma das plantas, obtendo-se a matéria fresca total das folhas. Logo após, de cada folha foram retirados três segmentos medindo $1 \mathrm{~cm}^{2}$ cada, pesados em balança analítica e calculada a média dos três segmentos. Dessa forma, a área foliar total era obtida por regra de 3 simples 
(MIELKE et al., 1995). De posse desses dados e da matéria seca, foram calculadas a razão de área foliar (RAF) e a área foliar específica (AFE), segundo Benincasa (1988).

Os dados foram submetidos à análise de variância, utilizando-se o software STATISTICA 6.0. Os dados do número de folhas foram transformados em $\sqrt{X+0,5}$ (ZAR, 1999) e as médias, comparadas entre si pelo teste de Tukey a 5\% probabilidade. No caso da área foliar, razão de área foliar e área foliar específica, os dados não mostraram distribuição normal. Para verificar diferenças nessas variáveis, foram utilizados testes não paramétricos, Kruskal-Wallis e teste de comparação de medianas (Median test).

\section{RESULTADOS E DISCUSSÃO}

\subsection{Altura, número de folhas e diâmetro do caule}

Ao final do experimento, foram verificadas diferenças significativas na altura das plantas, número de folhas e diâmetro do caule entre os diferentes tratamentos hídricos aplicados (Figura 1).

As plantas submetidas aos tratamentos-controle e $80 \%$ da CP apresentaram maiores valores de altura em relação aos outros tratamentos já a partir do $28^{\circ}$ dia após a diferenciação dos tratamentos (DAD) (Figura 1). Comparados ao controle, ocorreram reduções na altura de $27,2 \%$, 39,9\% e $57,6 \%$ nas plantas submetidas, respectivamente, a 60, 40 e $20 \%$ da CP e de 58,9\% nas plantas do tratamento SR. A reirrigação aplicada aos 30 DAD foi suficiente para que plantas, até então sem qualquer irrigação, apresentassem redução de 37,7\% em relação ao controle, similar à redução da altura das plantas mantidas com 40\% da CP (Figura 1).

Com relação ao número de folhas, diferenças significativas foram observadas a partir do $21^{\circ} \mathrm{DAD}$ (Figura 1). Ao fim do período experimental, apenas as plantas submetidas a $20 \%$ da CP e SR apresentaram menor número de folhas, em relação àquelas submetidas aos demais tratamentos hídricos, com reduções de 36,9\% e 33,6\%, respectivamente, quando comparadas com as plantas-controle. As plantas do tratamento $\mathrm{R}$ mostraram pequena recuperação na emissão de folhas novas, mas ainda insuficiente para apresentar valores mais elevados que as plantas do tratamento SR, tendo diminuído 29,4\% em relação ao tratamento-controle (Figura 1).

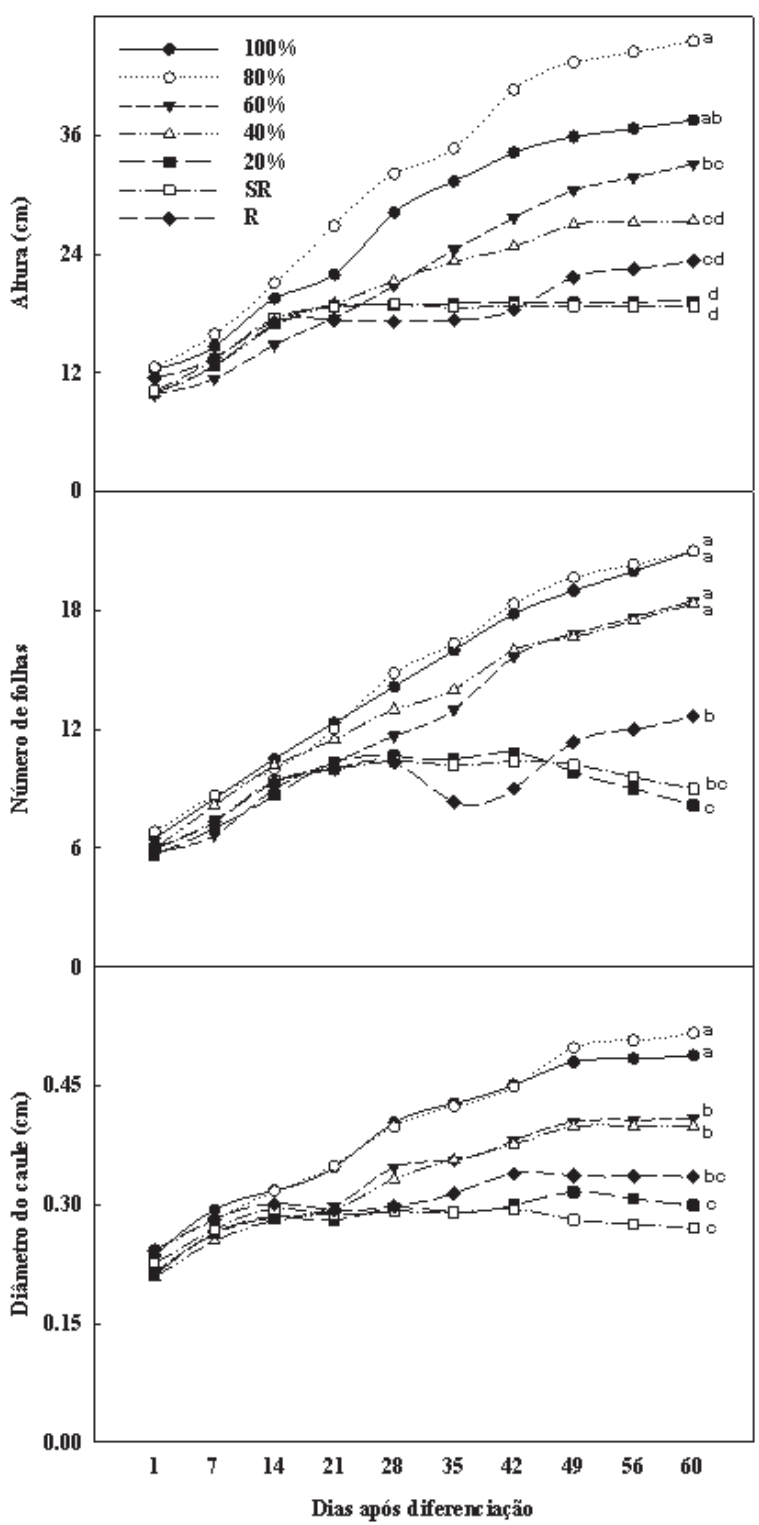

Figura 1 -Altura (cm), número de folhas e diâmetro do caule (cm) de plantas de nim-indiano (Azadirachta indica A. Juss) sob diferentes regimes hídricos (100 (controle), 80, 60, 40 e $20 \%$ da capacidade de pote (CP), suspensão de rega e reirrigado) cultivadas em casa de vegetação. Letras iguais indicam que não houve diferença significativa entre os tratamentos hídricos pelo teste de Tukey $(\mathrm{P}<0,05)$.

Figure 1 - Height (cm), leaf number and stem diameter of Neem seedlings (Azadirachta indica A. Juss) under differents water contents (100, 80, 60, 40 and $20 \%$ of field capacity, without water and re-watering) cultivated at greenhouse. Same letters means no difference between water regimes by the Tukey's test $(P<0,05)$.

Revista Árvore, Viçosa-MG, v.34, n.5, p.771-779, 2010 
O diâmetro do caule variou em função dos tratamentos (Figura 1). Ao final do experimento, as plantas do tratamento-controle e com $80 \%$ da CP foram as que apresentaram valores mais elevados do diâmetro do caule, seguidos pelas plantas dos tratamentos 60 e 40\% da CP, com valores intermediários e, por último, aquelas dos tratamentos com $20 \%$ da CP e SR. Em relação ao tratamento-controle, foram verificadas reduções de $16,1 \%, 18,2 \%, 38,7 \%$ e $44,6 \%$ nas plantas dos tratamentos $60 \%$, $40 \%$ e $20 \%$ da CP e SR, respectivamente. As plantas do tratamento $\mathrm{R}$ mostraram pequena recuperação ao final do experimento, quando apresentaram valores que diferiram apenas daqueles registrados em plantas mantidas com 100 e $80 \%$ da CP, mas ainda tendo redução de $31,3 \%$ em relação ao controle (Figura 1).

Velara e Cavagnaro (2006), estudando duas espécies do gênero Prosopis ( $P$. argentina e P. alpataco), observaram que a altura das plantas submetidas a déficit hídrico diminuiu significativamente a partir de 40 dias de aplicação dos tratamentos (Controle - 1L de água diariamente; e Estresse - $250 \mathrm{~mL}$ de água por dia). Resultados semelhantes foram encontrados por Figueirôa et al. (2004) ao trabalhar com plantas jovens de Myracrodruon urundeuva Allemão, submetidas a diferentes tratamentos hídricos. Esses autores verificaram reduções na altura das plantas estressadas, da ordem de $50 \%$ nas plantas do tratamento com $25 \%$ da capacidade de campo, aos 30 dias, e $22 \%$ nas plantas submetidas a 50\% da capacidade de campo avaliadas aos 60 dias. Os referidos autores encontraram reduções significativas também no número de folhas do tratamento mais severo, aos 30 e 60 dias.

A altura de plantas de Araucaria angustifolia (Bertol.) Kuntze também sofreu drástica diminuição a partir da suspensão da irrigação, mostrando diferença significativa já a partir de 35 dias (MÓSENA e DILLENBURG, 2004). Silva et al. (2002) encontraram reduções na altura das plantas e no diâmetro do caule e da copa de plantas de Melaleuca alternifolia Cheel sob déficit hídrico de aproximadamente 100 dias.

A queda de folhas mais velhas e a consequente redução no número de folhas é considerada, por Taiz e Zeiger (2004), reação comum das plantas em situações de déficit hídrico, quando a abscisão foliar é estimulada pela síntese acentuada e maior sensibilidade ao etileno.
Após deixar clones de eucaliptos sem irrigação, Reis et al. (2006) observaram reduções no diâmetro do caule (12,5\%, no máximo, respectivamente) em todos os clones avaliados em relação a plantas que estavam sendo irrigadas diariamente.

Nesta pesquisa, após a reposição aos 30 DAD as plantas do tratamento $\mathrm{R}$ mostraram recuperação no seu crescimento (Figura 1). Daudet et al. (2005) verificaram essa mesma resposta ao estudar o comportamento do diâmetro do caule de plantas de Juglans nigra, árvore nativa da França, submetidas à suspensão da irrigação por 10 dias e reirrigadas. Após a interrupção do estresse hídrico, essas plantas mostraram grande recuperação no crescimento do diâmetro do caule.

\subsection{Matéria Seca das Folhas, Caule e Raízes}

As plantas submetidas aos tratamentos-controle e $80 \%$ da CP apresentaram maiores valores de matéria seca de folhas, ou seja: de 2,827 e 3,492 g em média, respectivamente. Os tratamentos $60 \%$, 40\% e $20 \%$ da CP e SR tiveram valores de 2,115; 1,478; 0,502; e $0,784 \mathrm{~g}$, respectivamente. Desses, apenas as plantas dos tratamentos $20 \%$ da CP e SR não mostraram diferenças significativas. As plantas do tratamento $\mathrm{R}$ mostraram recuperação após a reirrigação, obtendo média de 1,307 g ao final do experimento, igualando-se estatisticamente ao tratamento com 40\% da CP (Figura 2). Com relação à matéria seca do caule (MSC), as plantas do tratamento com $80 \%$ da CP foram as que mostraram maiores valores, com valor médio de 1,963 g. As plantas do tratamento-controle ficaram estatisticamente abaixo dessas, com média de 1,447 g, e superiores às plantas dos outros tratamentos, que não mostraram diferenças significativas entre si. As médias encontradas nos tratamentos restantes foram de 0,$842 ; 0,852 ; 0,485$; 0,448; e 0,497 g para 60\%, 40\% e 20\% da CP, SR e R, respectivamente (Figura 2).

Já com relação à matéria seca da raiz (MSR), os maiores valores foram de 3,107 e 3,397 g nas plantas dos tratamentos-controle e $80 \%$ da $\mathrm{CP}$, respectivamente. As plantas dos tratamentos com 60 e $40 \%$ da CP tiveram comportamento intermediário, com médias de 1,980 e $2,272 \mathrm{~g}$, respectivamente, ficando estatisticamente diferentes apenas das plantas do tratamento SR, que foram as que apresentaram menores médias de MSR, com valor de 0,650g (Figura 2). 


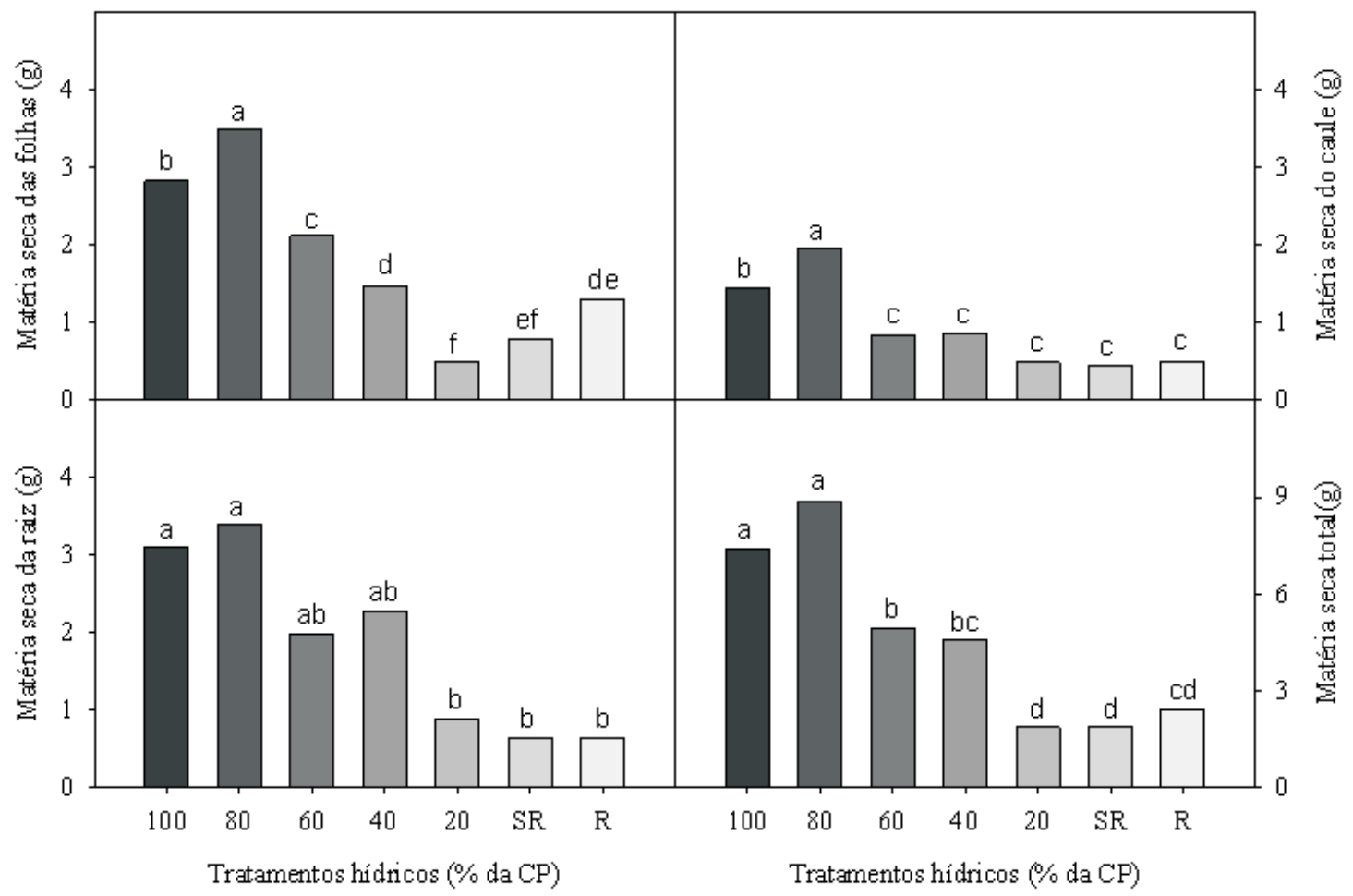

Figura 2 - Matéria seca das folhas (MSF), dos caules (MSC), das raízes (MSR) e total (MST) de plantas de nim-indiano (Azadirachta indica A. Juss) submetidas a diferentes tratamentos hídricos e cultivadas em casa de vegetação. Letras iguais indicam que não houve diferença significativa entre os tratamentos hídricos pelo teste de Tukey $(\mathrm{P}<0,05)$.

Figure 2 - Leaf, stem, roots and total dry mass of Neem seedlings (Azadirachta indica A. Juss) under differents water contents (100, 80, 60, 40 and 20\% of field capacity, without water and re-watering) cultivated at greenhouse. Same letters means no difference between water regimes by the Tukey's test $(P<0,05)$.

Avaliando a matéria seca total (MST), notou-se que os maiores valores foram encontrados nas plantas dos tratamentos-controle e com $80 \%$ da CP, com as respectivas médias de 7,380 e 8,851g. As plantas dos tratamentos com 60 e $40 \%$ da CP ficaram com valores intermediários de 4,936 e 4,601 g. As menores médias foram de 1,883 e 1,882g nas plantas dos tratamentos com $20 \%$ da CP e SR, respectivamente. As plantas reirrigadas mostraram recuperação, assemelhando-se estatisticamente às do tratamento com $20 \%$ da CP, com média de 2,440 g (Figura 2).

Villagra e Cavagnaro (2006) encontraram reduções na matéria seca de todos os órgãos e total de plantas jovens de $P$. argentina e $P$. alpataco submetidas a déficit hídrico por 96 dias. À semelhança deste resultado, Figueirôa et al., (2004) observaram reduções significativas nos tratamentos com 50 e $25 \%$ da capacidade de campo em relação à matéria seca das folhas, caule, raízes e total em plantas jovens de Myracrodruon urundeuva Allemão apenas aos 60 dias, não tendo encontrado diferenças significativas aos 30 dias de aplicação dos tratamentos.

Estudando os efeitos do estresse hídrico em plantas jovens de Dalbergia sissoo Roxb., Singh e Singh (2003) verificaram diferenças significativas na matéria seca das folhas, caule, raízes e total em todos os tratamentos hídricos, havendo crescente redução, de acordo com a severidade do estresse aplicado.

Como o estresse hídrico causado pela seca se desenvolve de maneira gradual, há sequência de eventos que ocorrem, sendo a primeira e a mais sensível resposta ao déficit hídrico a diminuição do processo de crescimento em consequência da diminuição da turgescência (LARCHER, 2006). Desse modo, justificam-se as reduções na MSF, MSC, MSR e MST, à medida que o estresse hídrico se torna mais severo.

Revista Árvore, Viçosa-MG, v.34, n.5, p.771-779, 2010 


\subsection{Alocação de biomassa das folhas (ABF), Caule (ABC) e Raízes (ABR)}

Nos tratamentos-controle, com $80 \%$ e $60 \%$ da CP, a alocação de biomassa das folhas ao final do experimento foi a mais alta, sendo de 38,9; 40,1; e 43,7\%, respectivamente. As plantas cultivadas no tratamento SR tiveram comportamento semelhante ao das controle, com média de $41,7 \%$ de biomassa nas folhas. O tratamento com $20 \%$ da CP foi o que teve as plantas que menos alocaram biomassa para as folhas, com valor médio de $27,7 \%$, respectivamente. Com relação ao caule, as plantas dos tratamentos-controle, e dos com 80, 60 e $40 \%$ da CP tiveram as menores médias, com 19,8, 22,1, 17,3 e 18,5\% de alocação de biomassa do caule (ABC), respectivamente. A maior alocação de biomassa para o caule foi verificada em plantas submetidas ao tratamento com $20 \%$ da CP, da ordem de $27,7 \%$ da massa total. As plantas do tratamento SR tiveram média de 24,1\% de biomassa no caule, sendo estatisticamente semelhantes às outras. Na raiz, não houve diferença estatística entre os tratamentos aplicados, exceto no R, no qual as plantas apresentaram reduções entre 41,2\% (controle) e 34\% (SR). As plantas reirrigadas elevaram a emissão de novas folhas após a reposição de água no solo, mostrando aumento na ABF (53,5\%), manutenção da ABC (20,3\%) e queda na ABR (26\%) (Figura 3).

Neste estudo, notamos facilmente que o estresse evidenciou-se em uma menor $\mathrm{ABF}$ à medida que a disponibilidade hídrica foi menor, exceto nas plantas do tratamento SR, onde não houve qualquer comportamento diferenciado. Percebe-se que as plantas do tratamento SR pararam de crescer porque tiveram seu processo fotossintético paralisado pela falta de água e, com isso, não tiveram como diferenciar a alocação de fotoassimilados, chegando ao final do experimento com comportamento similar ao das plantas controle. As plantas dos tratamentos com 40 e $20 \%$ da CP que tinham pouca água disponível revelaram a tendência de alocar mais fotoassimilados para as raízes, como tentativa de manutenção da absorção de água. Após a reirrigação, os dados de crescimento mostram que as plantas do tratamento $\mathrm{R}$ promoveram a emissão de novas folhas como forma de recuperação. Desta forma, podemos inferir que as plantas investiram na produção dos órgãos fotossintetizantes, que aproveitariam o momento de alta disponibilidade hídrica para produzir o máximo de fotoassimilados.

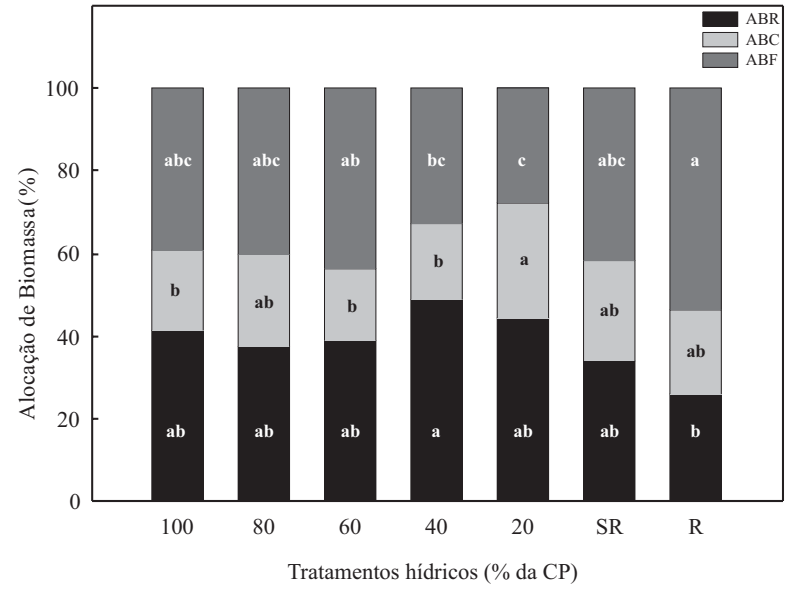

Figura 3 - Alocação de biomassa das folhas (ABF), caule (ABC) e raízes (ABR) de plantas de nim-indiano submetidas a diferentes regimes hídricos. Letras iguais indicam que não houve diferença significativa entre os tratamentos pelo teste de Tukey $(\mathrm{P}<0,05)$.

Figure 3 -Biomass allocation of leafs, stem and roots of neem seedlings under different water contents.Sameletters means no difference between water regimes by the Tukey's test $(P<0,05)$.

Singh e Singh (2003), aplicando diferentes regimes hídricos em mudas de Dalbergia sissoo Roxb., verificaram que houve aumento na alocação de biomassa para a raiz à medida que o estresse era mais severo, com consequente diminuição da matéria seca das folhas. Resultados semelhantes foram encontrados por Villagra e Cavagnaro (2006), quando verificaram maior ABR em duas espécies de Prosopis sp. submetidas à suspensão de irrigação.

\section{4. Área foliar, razão de área foliar e área foliar específica}

As plantas dos tratamentos com 80, 60 e 40\% da CP apresentaram valores de área foliar semelhante ao controle, enquanto as plantas dos tratamentos com $20 \%$ da CP e SR tiveram reduções de $88 \%$ e $86 \%$, respectivamente, em relação ao tratamento-controle. As plantas reirrigadas não demonstraram recuperação na área foliar (Tabela 1). Entretanto, as diferenças encontradas na área foliar não foram suficientes para causar alterações na razão de área foliar e área foliar específica, uma vez que a redução da área foliar foi acompanhada por reduções de mesma proporção na matéria seca das folhas e total. 
Tabela 1 - Área foliar, razão de área foliar (RAF) e área foliar específica (AFE) em plantas de nim-indiano (Azadirachta indica A. Juss) submetidas a diferentes regimes hídricos (100 (controle), 80, 60, 40 e 20\% da capacidade de pote (CP) esuspensão de rega e reirrigado), cultivadas em casa de vegetação.

Table 1 - Leaf area, leaf area ratio and specific leaf area of Neem seedlings (Azadirachta indica A. Juss) under differents water contents $(100,80,60,40$ and $20 \%$ of field capacity, without water and re-watering) cultivated at greenhouse

\begin{tabular}{lrrr}
\hline Tratamentos & Área foliar $\left(\mathrm{cm}^{2}\right)$ & RAF & AFE \\
\hline & & $\left(\mathrm{cm}^{2} \cdot \mathrm{g}^{-1} \mathrm{MS}\right)$ & $164,21 \mathrm{a}$ \\
\hline $100 \%$ da CP & $462,08 \mathrm{a}$ & $65,53 \mathrm{a}$ & $153,55 \mathrm{a}$ \\
$80 \%$ da CP & $522,58 \mathrm{a}$ & $59,51 \mathrm{a}$ & $163,96 \mathrm{a}$ \\
$60 \%$ da CP & $346,33 \mathrm{a}$ & $71,6 \mathrm{a}$ & $162,87 \mathrm{a}$ \\
$40 \%$ da CP & $248,08 \mathrm{a}$ & $52,65 \mathrm{a}$ & $84,18 \mathrm{a}$ \\
$20 \%$ da CP & $51,62 \mathrm{~b}$ & $22,56 \mathrm{a}$ & $106,78 \mathrm{a}$ \\
Suspensão de rega & $63,00 \mathrm{~b}$ & $36,25 \mathrm{a}$ & $69,58 \mathrm{a}$ \\
Reirrigado & $74,16 \mathrm{~b}$ & $32,53 \mathrm{a}$ & \\
\hline
\end{tabular}

Letras iguais indicam que não houve diferença significativa entre os tratamentos hídricos pelo teste de comparação de medianas (não-paramétrico).

Same letters means no difference between water regimes by median test (non-parametric).

De posse desses dados, pode-se inferir que as plantas jovens de nim-indiano não conseguem manter a produção de matéria seca quando tem sua área foliar reduzida. Silva et al. (2003) também encontraram os mesmos resultados em três das quatro espécies da caatinga avaliadas sob déficit hídrico. Esses autores concluíram que apenas Prosopis juliflora DC, que reduziu a razão de área foliar junto com a área foliar, teve maior eficiência foliar ao manter a produção de matéria seca com menor área foliar.

Liu e Stützel (2004) verificaram reduções na área foliar e área foliar específica de genótipos de Amarantáceas submetidas à suspensão de irrigação. Essas plantas, quando reirrigadas, retomavam o crescimento e se igualavam às plantas irrigadas normalmente. Villagra e Cavagnaro (2006) também observaram reduções na área foliar de plantas de Prosopis sp. sem água disponível, mas não encontraram diferenças na área foliar específica dessas mesmas plantas, resultado semelhante ao deste trabalho.

Lopes et al. (2007), avaliando mudas de Eucalyptus grandis sob diferentes lâminas de irrigação, verificaram que a área foliar das mudas submetidas a lâmina de irrigação de $6 \mathrm{~mm}_{\text {.dia }}{ }^{-1}$ foi, em média, 53\% menor que as plantas do tratamento-controle (lâmina de irrigação de $14 \mathrm{~mm} \cdot \mathrm{dia}^{-1}$ ).

Figuerôa et al. (2004) afirmaram que a umidade do ambiente é que determina a área foliar de uma planta, sendo maior em ambientes úmidos e menor em ambientes áridos. Essa característica é importante defesa contra a perda excessiva de água, e a diminuição da área foliar está entre as várias características xeromórficas que são identificadas em vegetais sob déficit hídrico (VILLAGRA e CAVAGNARO, 2006).

\section{CONCLUSÕES}

1. Níveis de água abaixo de $60 \%$ da CP reduzem significativamente o crescimento e a produção de matéria seca do nim-indiano;

2. Sob baixa disponibilidade hídrica ocorre redução da matéria seca das folhas e da área foliar, podendo essas variáveis ser utilizadas como parâmetros de avaliação desta espécie ao déficit hídrico;

3. A recuperação das plantas reirrigadas foi evidenciada por meio da emissão de novas folhas, confirmada principalmente pelo aumento na alocação de biomassa para as folhas destas plantas; e

4. Plantas jovens de nim-indiano devem ser cultivadas a $80 \%$ da capacidade de pote para máximo de crescimento e menores gastos com irrigação.

\section{REFERÊNCIAS BIBLIOGRÁFICAS}

ARAÚJO, L. V. C.; RODRIGUEZ, L. C. E.; PAES, J. B. Características físico-químicas e energéticas da madeira de nim-indiano. Scientia Forestalis, n. 57, p. 153-159, 2000.

BENINCASA, M.M.P. Análise de crescimento de plantas. 1 . ed. Jaboticabal: FUNEP, 1988. 42p.

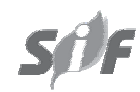

Revista Árvore, Viçosa-MG, v.34, n.5, p.771-779, 2010 
DAUDET, F.; AMÉGLIO, T.; COCHARD, H.; ARCHILLA, O.; LACOINTE, A.

Experimental analysis of the role of water and carbon in tree stem diameter variations. Journal of Experimental Botany, v. 56, n. 409, p. 135-144, 2005.

FIGUEIRÔA, J. M.; BARBOSA, D. C. A.; SIMABUKURO, E. A. Crescimento de plantas jovens de Myracrodruon urundeuva Allemão (Anacardiaceae) sob diferentes regimes hídricos. Acta Botanica Brasílica, v. 18, n. 3, p. 573-580, 2004.

GRIFFITHS, H.; PARRY, M. A. J. Plant responses to water stress. Annals of Botany, v. 89, p. 801-802, 2002.

JONES, H. G. Monitoring plant and soil water status: established and novel methods revisited and their relevance to studies of drought tolerance. Journal of Experimental Botany, v. 58, n. 2, p. 119-130, 2007.

KULKARNI, A. R.; SOPPIMATH, K. S.; AMINABHAVI, T. M. Solubility Study of Azadirachta indica A. Juss. (Neem) Seed Oil in the Presence of Cosolvent/Nonionic Surfactant at $(298.15,303.15,308.15$, and 313.15) K. Journal of Chemistry Engineering Data, v. 44, p. 836-838, 1999.

LARCHER, W. Ecofisiologia vegetal. Tradução: Prado, C. H. B. A. São Carlos: Ed. Rima, 2006. 531p.

LIU, F.; STÜTZEL, H. Biomass partitioning, specific leaf area, and water use efficiency of vegetable amaranth (Amaranthus spp.) in response to drought stress. Scientia Horticulturae, v. 102, p. 15-27, 2004.

LOPES, J. L. W.; GUERRINI, I. A.; SAAD, J. C. C. Qualidade de mudas de eucalipto produzidas sob diferentes lâminas de irrigação e dois tipos de substrato. Revista Árvore, v. 31, n. 5, p. 835-843, 2007.

LUU, D. T.; MAUREL, C. Aquaporins in a challenging environment: molecular gears for adjusting plant water status. Plant, Cell and Environment, v. 28, p. 85-96, 2005.
MIELKE, M. S.; HOFFMAN, A.; ENDRES, L.; FACHINELLO, J. C. Comparação de métodos de laboratório e de campo para estimativa da área foliar em fruteiras silvestres. Scientia Agricola, v. 52, n. 1, p. 82-88, 1995.

MÓSENA, M.; DILLENBURG, L. R. Early growth of Brazilian pine (Araucaria angustifolia [Bertol.] Kuntze) in response to soil compaction and drought. Plant and Soil, v. 258, p. 293-306, 2004.

NOGUEIRA, R. J. M. C.; ALBUQUERQUE, M. B.; SILVA, E. C. Aspectos ecofisiológicos da tolerância à seca em plantas da caatinga. In: NOGUEIRA, R. J. M. C.; ARAÚJO, E. L.; WILLADINO, L. G.; CAVALCANTE, U. M. T. Estresses ambientais: danos e benefícios em plantas. Recife: UFRPE, Imprensa Universitária, 2005. p.22-31.

OKEMO, P. O.; MWATHA, W. E.; CHHABRA, S. C.; FABRY, W. The kill kinetics of Azadirachta indica A. Juss. (Meliaceae) extracts on Staphylococcus aureus, Escherichia coli, Pseudomonas aeruginosa and Candida albicans. African Journal of Science and Technology, v. 2, n. 2, p. 113-118, 2001.

PIMENTEL, C. A relação da planta com a água. Rio de Janeiro: Seropédica, 2004. 191 p.

REIS, G. G.; REIS, M. G. F.; FONTAN, I. C. I.; MONTE, M. A.; GOMES, A. N.; OLIVEIRA, C. H. $\mathrm{R}$. Crescimento de raízes e da parte aérea de clones de híbridos de Eucalyptus grandis $\mathrm{x}$ Eucalyptus urophylla e de Eucalyptus camaldulensis x Eucalyptus spp submetidos a dois regimes de irrigação no campo. Revista Árvore, v. 30, n. 6, p. 921-931, 2006.

ROOP, J. K.; DHALIWAL, P. K.; GURAYA, S. S. Extracts of Azadirachta indica and Melia azedarach seeds inhibit folliculogenesis in albino rats. Brazilian Journal of Medical and Biological Research, v. 38, p. 943-947, 2005.

SADRAS, V. O.; MILROY, S. P. Soil-water thresholds for the responses of leaf expansion and gas exchange: A review. Field Crops Research, v. 47, p. 253-266, 1996.

SILVA, E. C.; NOGUEIRA, R. J. M. C. Crescimento de quatro espécies lenhosas cultivadas sob estresse hídrico em casa-de-vegetação. Ceres, v. 50, n. 288, p. 203-217, 2003. 
SILVA, S. R. S.; DEMUNER, A. J.; BARBOSA, L. C. A.; CASALI, V. W. D.; NASCIMENTO, E. A.; PINHEIRO, A. L. Efeito do estresse hídrico sobre características de crescimento e a produção de óleo essencial de Melaleuca alternifolia Cheel. Acta Scientiarum, v. 24, n. 5, p. 1363-1368, 2002.

SINGH, B.; SINGH, G. Biomass partitioning and gas exchange in Dalbergia sissoo seedlings under water stress. Photosynthetica, v.41, n.3, p. 407-414, 2003.

SOUZA, C. C.; OLIVEIRA, F. A.; SILVA, I. F.; AMORIM NETO, M. S. Avaliação de métodos de determinação de água disponível e manejo da irrigação em terra roxa sob cultivo de algodoeiro herbáceo. Revista Brasileira de

Engenharia Agrícola e Ambiental, v. 4, n. 3, p. 338-342, 2000.

TAIZ, L.; ZEIGER, E. Fisiologia vegetal. Porto Alegre: Artmed Editora, 2004. 719p.
TYERMANN, S. D.; NIEMIETZ, C. M.; BRAMLEY, H. Plant aquaporins: multifunctional water and solute channels with expanding roles. Plant, Cell and Environment, v. 25, p. 173-194, 2002.

VILLAGRA, P. E.; CAVAGNARO, J. B. Water stress effects on the seedling growth of Prosopis argentina and Prosopis alpataco. Journal of Arid Environments, v. 64, p. 390-400, 2006.

WEWETZER, A. Callus cultures of Azadirachta indica and their potential for the production of Azadirachtin. Phytoparasitica, v. 26, n. 1, p. 47-52, 1998.

YORDANOV, I.; VELIKOVA, V.; TSONEV, T. Plant responses to drought, acclimation and stress tolerance. Photosynthetica, v. 38, n. 1, p. 171-186, 2000.

ZAR, J. H. Biostatiscal Analyses. New Jersey: Prentice Hall, 1999. 663p. 